\title{
Cost-Effectiveness Analysis of Sequential Biologic Therapy with Ixekizumab Versus Secukinumab in the Treatment of Active Psoriatic Arthritis with Concomitant Moderate-to-Severe Psoriasis in the UK
}

\author{
Bernd Schweikert ${ }^{1}$ (1) Chiara Malmberg ${ }^{1} \cdot$ Örjan Åkerborg $^{2} \cdot$ Gayathri Kumar $^{3} \cdot{\text { Debby } \text { Nott }^{3} \text {. Sandeep Kiri }}^{3}$. \\ Christophe Sapin ${ }^{4}$. Susanne Hartz ${ }^{5}$
}

Published online: 12 March 2020

(C) The Author(s) 2020

\begin{abstract}
Background Interleukin-17A (IL-17A) antagonists are a recent innovation for treating psoriatic arthritis (PsA). There are currently no cost-effectiveness analyses (CEAs) comparing the IL-17A antagonists ixekizumab and secukinumab in PsA from a UK perspective.

Objective We conducted a CEA from the UK National Health Service perspective to compare ixekizumab versus secukinumab in patients with PsA and concomitant moderate-to-severe plaque psoriasis.

Methods A Markov model was developed based on the widely accepted York model. In biologic disease-modifying antirheumatic drug (bDMARD)-naïve patients, ixekizumab $\rightarrow$ ustekinumab $\rightarrow$ best supportive care (BSC) was compared with secukinumab $\rightarrow$ ustekinumab $\rightarrow$ BSC. For bDMARD-experienced patients, ixekizumab $\rightarrow$ BSC was compared with secukinumab $\rightarrow$ BSC. At the end of the bDMARD trial period, Psoriatic Arthritis Response Criteria (PsARC) responders continued to receive the bDMARD in the continuous treatment period. PsARC nonresponders and patients who ceased continuous treatment transitioned to the trial period of the next treatment.

Results Ixekizumab was less costly and provided more quality-adjusted life-years (QALYs) than secukinumab in bDMARDnaïve and -experienced patients based on list prices, although cost savings and QALY gains were small to modest. In bDMARD-naïve patients, total costs were $£ 155,455$ compared with $£ 155,530$ for secukinumab (year 2017 values). Total QALYs were 8.127 versus 7.989. In bDMARD-experienced patients, the corresponding values were $£ 140,051$ versus $£ 140,264$ for total costs and 3.996 versus 3.875 for total QALYs.

Conclusion Ixekizumab provided more QALYs at a marginally lower cost than secukinumab, and the results were most sensitive to changes in drug costs. Other factors, such as patient preferences for the number of injections and confidential price discounts, may be important considerations in clinical decision-making.
\end{abstract}

Keywords Cost-effectiveness analysis $\cdot$ Psoriatic arthritis $\cdot$ Psoriasis $\cdot$ Ixekizumab $\cdot$ Secukinumab $\cdot$ Biologic $\cdot$ Sequential

Electronic supplementary material The online version of this article (https://doi.org/10.1007/s41669-020-00202-1) contains supplementary material, which is available to authorized users.

Bernd Schweikert

bernd.schweikert@iconplc.com

ICON Plc, Konrad-Zuse-Platz 11, 81829 Munich, Germany

ICON Plc, Stockholm, Sweden

Eli Lilly and Company Ltd, Basingstoke, UK

4 Eli Lilly and Company, Neuilly-sur-Seine, France

5 Eli Lilly and Company Ltd, Windlesham, UK

\section{Introduction}

Psoriatic arthritis (PsA) is a heterogeneous chronic inflammatory rheumatic disease that affects $\approx 0.25 \%$ of the population and is characterized by pain, stiffness, swollen joints, joint erosion, and bone formation $[1,2]$. In the UK, the prevalence of psoriatic arthritis is estimated to be approximately $0.1-0.3 \%$ of the population [3]. PsA commonly coexists with psoriasis [1, 2]. In particular, moderate-to-severe PsA is associated with reduced health-related quality of life and substantial healthcare resource use and costs [4-7]. 


\section{Key Points for Decision Makers}

This CEA compares ixekizumab and secukinumab in PsA in the UK; this comparison to secukinumab was considered particularly relevant in a decision-making context (i.e. they have the same mechanism of action and are both recommended by NICE under similar conditions of use).

In both bDMARD-naïve and -experienced patients with PsA and concomitant moderate-to-severe psoriasis, ixekizumab provided more QALYs at a lower cost than secukinumab.

Although gains with ixekizumab were modest, the findings of this CEA, along with patient preferences and other factors, may be helpful in clinical decision-making.

Several biologic disease-modifying antirheumatic drugs (bDMARDs) are approved for treating patients with PsA. bDMARDs are major drivers of total costs in the management of PsA [6, 8]; for example, they accounted for approximately $70 \%$ of the total direct cost of PsA in a large US cohort [8]. The use of bDMARDs in the UK is under increasing scrutiny, especially given the advent of biosimilars and the growing number of biologic agents. Among the interleukin (IL) antagonists that are reimbursed in the UK, the most recently introduced agent is ixekizumab, a highaffinity monoclonal antibody that selectively targets IL-17A, a proinflammatory cytokine implicated in the pathogenesis of psoriatic arthritis [1,9]. Secukinumab, another IL-17A antagonist, is among the most recently approved bDMARDs for PsA, and is indicated at a dosage of $300 \mathrm{mg}$ (at weeks 0 , $1,2,3$ and 4, followed by monthly maintenance dosing) for patients with concomitant moderate-to-severe psoriasis [10].

To address the lack of published cost-effectiveness analyses (CEAs) of ixekizumab in PsA in the UK, we conducted a CEA from the perspective of the UK National Health Service (NHS) using an adaptation of the economic framework of the most recent version of the York model, as the York model and updated versions of it are considered the 'gold standard' in this setting [11-13]. We aimed to assess the cost-effectiveness of ixekizumab versus secukinumab in patients with PsA and concomitant moderate-to-severe plaque psoriasis. Secukinumab was selected as a comparator because both agents have similar mechanisms of action and have demonstrated efficacy in PsA and plaque psoriasis $[9,10]$, so decision-makers may wish to select between these IL-17A antagonists. In addition, both drugs are recommended by NICE in the UK under similar conditions of use in the treatment of patients with active PsA after conventional DMARDs $[14,15]$.

\section{Methods}

\subsection{Model Overview}

A Markov model was developed to compare the cost-effectiveness of ixekizumab versus secukinumab in a hypothetical cohort of adult patients with active PsA and concomitant moderate-to-severe plaque psoriasis in the UK, although the model can also be adapted for use in other countries. The model used a framework similar to that of the York model developed by Woolacott et al. [11], which has been widely used and is accepted as being relevant to PsA by NICE in the UK $[12,13]$. Specifically, the model structure is closely aligned with that of the most recent version of the York model, which was used to evaluate the cost-effectiveness of various bDMARDs in patients with PsA and allowed further classification according to the level of concomitant psoriasis [13]. Like the York model, our model facilitates the analysis of treatment sequences, but it also allows for the application of a composite response criterion, so that treatment success can be evaluated based on both joint and skin symptoms (Table S1 in the Electronic supplementary material, ESM). The model includes four health states: bDMARD trial period, continuous bDMARD treatment, best supportive care (BSC) and death. The analysis used a lifetime horizon in the base case, in line with previous models [12, 13, 16-19]. The model incorporated mortality data for the normal UK population [20] adjusted for an increased disease-specific mortality risk [21] regardless of whether patients respond to treatment.

\subsection{Treatment Sequences}

The treatment sequences evaluated in the model were ixekizumab followed by ustekinumab then BSC versus secukinumab followed by ustekinumab then BSC in bDMARDnaïve patients, and ixekizumab followed by BSC versus secukinumab followed by BSC in bDMARD-experienced patients. The treatment sequence approach is reflective of clinical practice in the UK with potential variation in bDMARD treatment algorithms [22, 23]. Dosage regimens for all agents were as per European Medicines Agency labelling (Table 1). The trial period reflected the treatment continuation rule for therapies recommended by NICE in England and Wales, and was 16 weeks for ixekizumab and secukinumab and 24 weeks for ustekinumab. The model used monthly cycles. No half-cycle correction was applied because the cycle length was deemed sufficiently short compared to the length of the time horizon [24-26].

At the end of the trial period with initial bDMARD treatment, Psoriatic Arthritis Response Criteria (PsARC) responders transitioned to continuous treatment on the same drug and were assumed to maintain the same level of 
Table 1 Treatment sequences and dosage regimens (all interleukin antagonists were administered subcutaneously)

\begin{tabular}{|c|c|c|}
\hline First-line treatment & Second-line treatment & $\begin{array}{l}\text { Third-line } \\
\text { treatment }\end{array}$ \\
\hline \multicolumn{3}{|l|}{ bDMARD-nä̈ve patients } \\
\hline $\begin{array}{l}\text { Ixekizumab } 80 \mathrm{mg} \text { Q2W/ } \\
\text { Q4W }\end{array}$ & $\begin{array}{l}\text { Ustekinumab } 45 \mathrm{mg} \\
\text { Q12W }\end{array}$ & $\mathrm{BSC}$ \\
\hline $\begin{array}{l}\text { Secukinumab } 300 \mathrm{mg} \\
\text { monthly }^{\mathrm{c}}\end{array}$ & Ustekinumab as above & BSC \\
\hline \multicolumn{3}{|c|}{ bDMARD-experienced patients ${ }^{\mathrm{d}}$} \\
\hline $\begin{array}{l}\text { Ixekizumab } 80 \text { mg Q2W/ } \\
\text { Q4W }\end{array}$ & BSC & \\
\hline $\begin{array}{l}\text { Secukinumab } 300 \mathrm{mg} \\
\text { monthly }\end{array}$ & BSC & \\
\hline
\end{tabular}

DDMARD biologic disease-modifying antirheumatic drug, BSC best supportive care, $Q x W$ every $x$ weeks; $S C$ subcutaneously, $T N F$ tumour necrosis factor

${ }^{a}$ Ixekizumab regimen specifically for patients with PsA and concomitant moderate-to-severe plaque psoriasis; an initial loading dose of $160 \mathrm{mg}$ is administered at week 0 , followed by an $80 \mathrm{mg}$ dose at weeks 2, 4, 6, 8, 10 and 12, and thereafter Q4W

${ }^{\mathrm{b}}$ Ustekinumab $45 \mathrm{mg} \mathrm{SC}$ at week 0 and 4 , then $45 \mathrm{mg} \mathrm{SC} \mathrm{Q12W}$ in patients with body weight $<100 \mathrm{~kg}$. In patients with body weight $>$ $100 \mathrm{~kg}$, the license states that the $90 \mathrm{mg}$ dose may be used. No relevant clinical data pertaining to the $90 \mathrm{mg}$ dose were identified that could inform the evidence syntheses; therefore, only the $45 \mathrm{mg}$ dose was considered in the analyses. In the UK, ustekinumab $90 \mathrm{mg}$ is recommended for use by NICE under a patient access scheme in which it is supplied by the manufacturer at the same cost as the $45 \mathrm{mg}$ dose [46]

${ }^{\mathrm{c}}$ Secukinumab regimen specifically for patients with PsA and concomitant psoriasis or inadequate response to TNF inhibitors; an initial loading dose of $300 \mathrm{mg}$ was administered at week 0 , followed by a $300 \mathrm{mg}$ dose at weeks 1, 2, 3 and 4, and thereafter $300 \mathrm{mg}$ monthly

${ }^{\mathrm{d}}$ Dosage regimens as for bDMARD-naïve patients

response until discontinuation. PsARC response is based on improvement from baseline in two of the following four criteria (one of which must be a joint count) without worsening in any measure: tender/swollen joints and physician/patient global assessment of disease severity [27, 28]. PsARC nonresponders and patients who ceased continuous therapy transitioned to the trial period of the next bDMARD treatment or BSC if they discontinued the last treatment in the sequence. An annual all-cause discontinuation rate of $16.5 \%$ was assumed for bDMARD continuous therapy, in accordance with previous models and consistent with recent NICE submissions $[12,13]$. In the absence of drug-specific data, this discontinuation rate was applied uniformly across all bDMARD comparators and treatment lines and assumed to be independent of Health Assessment Questionnaire (HAQ) and Psoriasis Area and Severity Index (PASI) scores. In patients with PsA, the HAQ is commonly used to assess physical function, and focuses on physical disability and pain $[29,30]$. PASI is a measurement of disease severity based on psoriasis symptoms. In the bDMARD-naïve subgroup, following nonresponse to or discontinuation of the last (i.e. second) bDMARD, patients transitioned to BSC (Fig. 1). In the bDMARD-experienced subgroup, patients transitioned to BSC after nonresponse to or discontinuation of the first (i.e. only) bDMARD in the treatment sequence. Patients could transition to death from any health state.

\subsection{Alternative Response Criteria}

As an alternative to the PsARC response criterion, the model also allows the use of a composite response criterion that combines the PsARC and PASI criteria, thereby capturing both joint and skin response in patients with PsA (Fig. 2). Although treatment decisions will likely be based predominantly on joint response in most clinical settings, it is noteworthy that NICE guidance suggests that patients whose disease has a PASI75 response $(\geq 75 \%$ reduction in baseline PASI) but whose PsARC response does not justify continuing treatment should be assessed by a dermatologist to determine whether continuing treatment is appropriate based on skin response [15]. Skin response might also play a greater role in combined dermatology/rheumatology clinics. The IL-17A antagonists and other recent bDMARDs have demonstrated robust efficacy with respect to PASI (in addition to PsARC) in PsA [13, 31-33]. While the model allows different levels of PASI response to be used (at least a $75 \%, 90 \%$ or $100 \%$ reduction in baseline PASI; i.e. PASI75, PASI90 or PASI100) as part of the composite response assessment, the presented analyses use PsARC and PASI75 to reflect the respective NICE recommendation [15]. The model was programmed in Visual Basic for Applications and had a Microsoft ${ }^{\circledR}$ Excel-based user interface.

\subsection{Target Population}

The target population was patients with active PsA and concomitant moderate-to-severe psoriasis, defined as $\geq 3 \%$ of body surface area and PASI $>10$. In the base-case analysis, the model incorporated demographic data that were pooled from the randomised, placebo-controlled SPIRIT-P1 and SPIRIT-P2 intent-to-treat trials (Table 2) that evaluated the efficacy of ixekizumab in bDMARD-naïve [31] and -experienced [32] patients with PsA. The model incorporates these two subpopulations based on prior therapy. EULAR guidelines note that bDMARD-experienced patients generally have lower response rates than bDMARD-naïve patients in this setting [34]. In addition, the model allows for further stratification by degree of skin involvement (no psoriasis, mild psoriasis, moderate-to-severe psoriasis); moderate-tosevere psoriasis is the focus of the current analysis. 
A

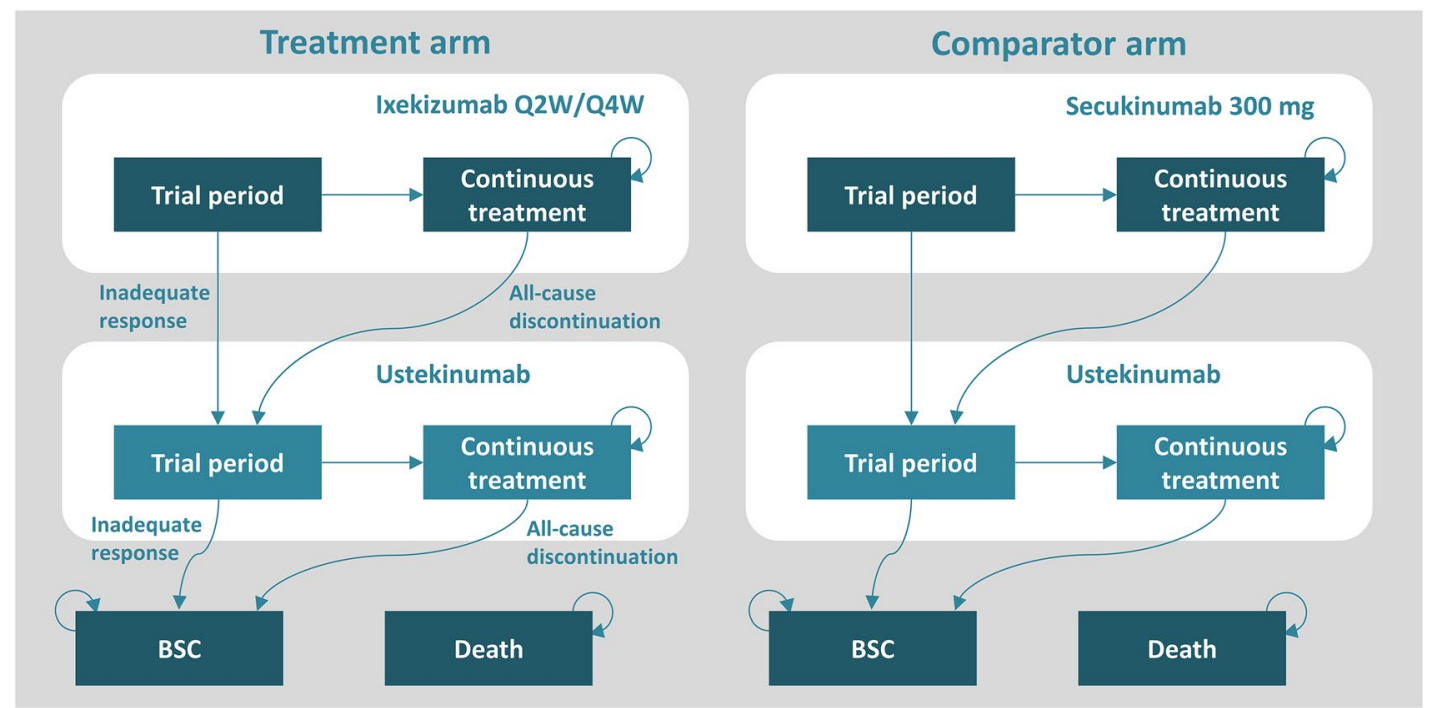

B

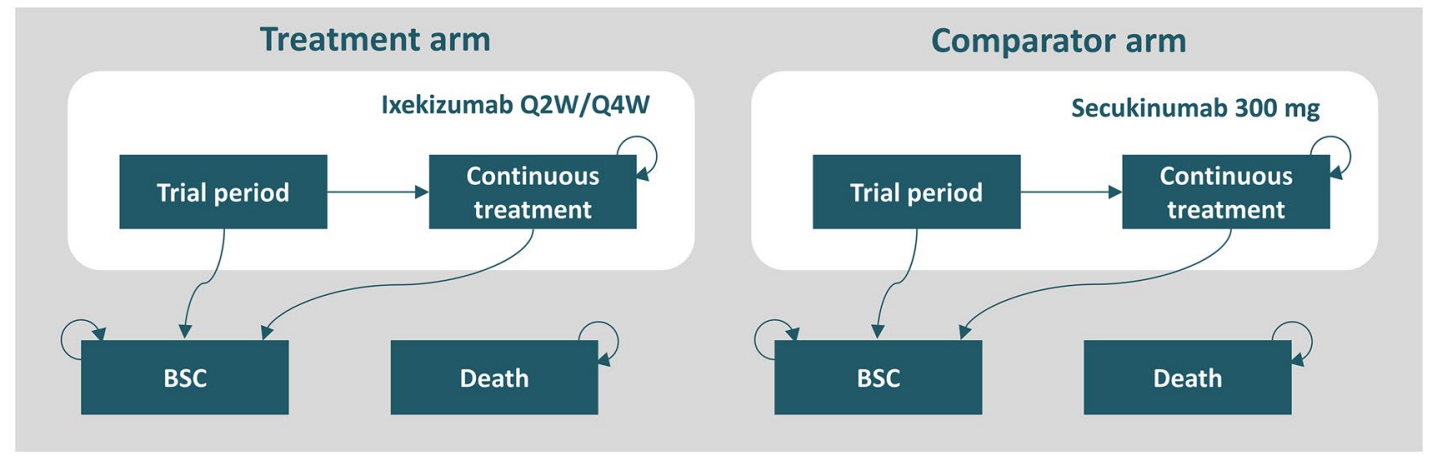

Fig. 1 Schematic representation of the model structure in (a) bDMARD-naïve patients and (b) bDMARD-experienced patients. Although not shown in the figure, patients could transition to death from any state. BSC best supportive care, $Q x W$ every $x$ weeks

\subsection{Treatment Effect}

While the response criteria (PsARC alone or PsARC and PASI) determine whether bDMARD treatment will be continued or discontinued in the model, the clinical effect of treatment is modelled as changes in baseline HAQ and PASI scores. For each bDMARD treatment, the proportion of responding patients and the magnitude of the treatment effects (i.e. changes in HAQ and PASI scores) were derived from a network meta-analysis (NMA) [35] that informed the NICE submission for ixekizumab in PsA and included data from the ixekizumab SPIRIT clinical trial programme [31, 32]. Key efficacy input data derived from the meta-analysis and used in the base-case model are provided in Table S2 of the ESM.

Generally, to account for the effect of prior treatment on the effectiveness of subsequent treatment, the firstline treatment was run using data from bDMARD-naïve patients whereas the second-line treatment used data from bDMARD-experienced patients (contingent on data availability). In all cases, improvements (i.e. reductions) in
HAQ and PASI scores were greater for responders than nonresponders. For all bDMARDs, the treatment effect was assumed to be instantaneous; therefore, utilities at the end of the trial period were applied retrospectively throughout the trial period because data are not available for earlier timepoints across treatments. Baseline HAQ and PASI scores for bDMARD-naïve and -experienced patients, stratified according to psoriasis severity, were derived from the SPIRIT clinical trial programme with ixekizumab $[31,32]$. The clinical time points in the NMA were used to approximate treatment-specific time to first assessment. This trial period was 16 weeks for the IL-17 agents and 24 weeks for ustekinumab.

For responders to the chosen criteria (PsARC alone or PsARC and PASI), the initial improvement in HAQ was maintained during continuous treatment and, in the basecase analysis, reverted to baseline at discontinuation. Two alternative rebound scenarios were evaluated as sensitivity analyses: rebound to natural history (HAQ score returns to the level it would have been had the patient not responded at all to the bDMARD) and rebound to less than initial gain 


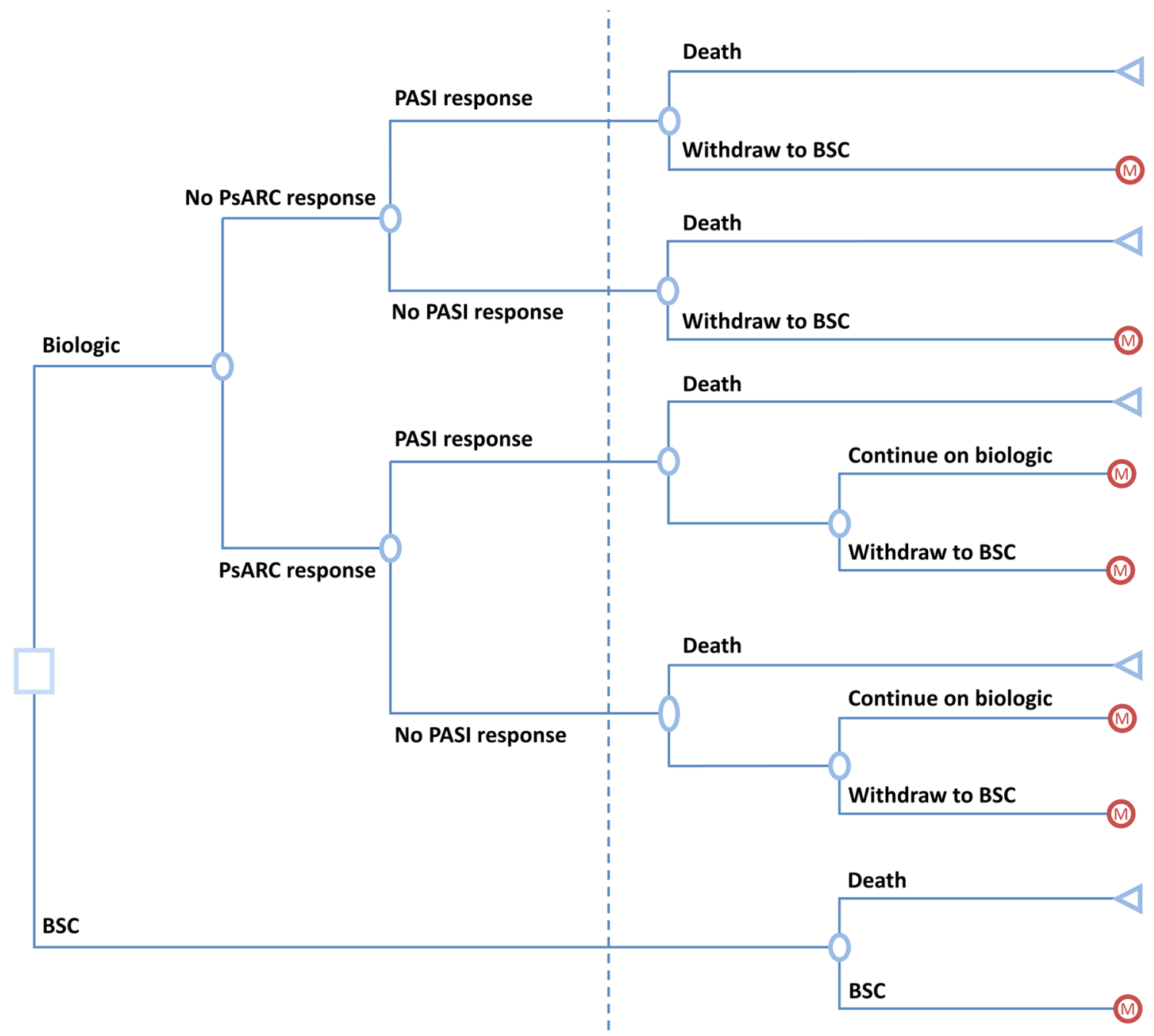

Fig. 2 Model structure for the trial period when combining PsARC and PASI response criteria. BSC best supportive care, PASI Psoriasis Area and Severity Index, PsARC Psoriatic Arthritis Response Criteria

Table 2 Characteristics of the target patient population (patients with PsA and concomitant moderate-to-severe psoriasis) based on pooled data from the SPIRIT-P1 and SPIRIT-P2 intent-to-treat trial populations $[28,29]$

\begin{tabular}{ll}
\hline Parameter & Mean value \\
\hline Age & 51.0 years \\
Proportion male & $51.84 \%$ \\
Proportion female & $48.16 \%$ \\
Body weight & $87.0 \mathrm{~kg}$ \\
bDMARD-nä̈ve patients & \\
Baseline HAQ score & 1.19 \\
Baseline PASI score & 20.4 \\
bDMARD-experienced patients & \\
Baseline HAQ score & 1.16 \\
Baseline PASI score & 23.4 \\
\hline
\end{tabular}

DDMARD biologic disease-modifying antirheumatic drug, $H A Q$ Health Assessment Questionnaire, PASI Psoriasis Area and Severity Index, $P s A$ psoriatic arthritis
(HAQ rebounds to $50 \%$ of initial gain, i.e. a level that is lower/better than baseline). Non-responders discontinued therapy after the trial period. In the base case, for patients who progressed to BSC, the HAQ score rebounded to the baseline HAQ level they had prior to starting the discontinued bDMARD ('rebound equal to initial gain'), although this assumption was modifiable in a sensitivity analysis. Irrespective of the rebound assumption, in the base-case analysis, patients were thereafter modelled to progress at the same rate as natural history progression $(0.018$ per 3 -month period) until the HAQ score reached its upper bound of 3.0. This follows the same approach developed in a previous version of the York model, and is based on data from the Norfolk Arthritis Register [12].

With respect to changes in PASI scores, irrespective of the PsARC response, the model assumed there was some improvement in PASI even among PASI nonresponders if a PASI threshold of 75 or higher was chosen. For example, if 
using the PsARC and PASI75 response criteria, the model allowed for some average improvement in nonresponders by taking into account the improvement in patients who reached a PASI between 50 and $75 \%$. Conversion of relative PASI improvements to absolute levels for PASI nonresponders as well as for responders was calculated as a weighted mean of PASI response categories above or below the selected criterion according to previously applied methods [13].

If the sole response criterion PsARC is chosen, the corresponding changes in PASI scores are modelled assuming a treatment-independent correlation between PsARC and PASI response. Following a previously applied approach, a correlation coefficient of rho $=0.4$ was assumed for the correlation between PsARC and PASI75 [12].

When patients are on continuous treatment, the mean absolute PASI score was assumed to remain constant at the level achieved at the end of the trial period. PASI levels were assumed to return to baseline values following discontinuation of bDMARD therapy. Patients in the BSC state were assumed to achieve the same level of PASI response as observed in the placebo arms of the clinical trials included in the NMA [35].

\subsection{Health-Related Quality of Life: Assignment of Health Utilities}

Health utilities were based on HAQ and PASI scores from the SPIRIT-P1 and -P2 clinical trials [31, 32] with UK tariffs applied. Calculation of utilities followed the established methodology of mapping the three-level version of EuroQol-5 Dimensions (EQ-5D-3L) utilities onto HAQ and PASI scores using a parsimonious linear regression model without further covariates or interaction terms [13]. Alternative coefficients based on a similar algorithm that used different data were applied in a sensitivity analysis. Utilities were calculated in each model cycle by multiplying HAQ and PASI levels by the estimated regression coefficients.

\subsection{Resource Use and Costs}

Only direct medical costs were included in the model, as the analysis was conducted from the perspective of the NHS in the UK. Resource use associated with subcutaneous bDMARDs during the trial and continuous treatment periods included physician visits, injection training and monitoring (Table 3). Resource use estimates were derived from relevant technology appraisals $[13,36]$ and are in line with guidelines from the British Society for Rheumatology for the use of bDMARDs [37]. Thus, resource-use assumptions are in line with prior modelling and are reflective of clinical practice.

Table 4 provides drug acquisition costs (year 2017 values) and costs of physician visits, injection training and
Table 3 Resource use for subcutaneous bDMARDs (adapted from [13]) during the trial period and annual resource use during the continuous treatment period

\begin{tabular}{lll}
\hline Resource & Trial period & $\begin{array}{l}\text { Continuous treat- } \\
\text { ment period (annu- } \\
\text { ally) }\end{array}$ \\
\hline $\begin{array}{l}\text { Rheumatologist visit } \\
\text { Injection training }\end{array}$ & 2 & 0 \\
Monitoring & 1 & 0 \\
FBC & 2 & \\
LFT & 2 & 2 \\
U\&E & 2 & 2 \\
ESR & 2 & 2 \\
Chest X-ray & 1 & 2 \\
TB Heaf test & 1 & 0 \\
ANA test & 1 & 0 \\
ds DNA test & 1 & 0 \\
\end{tabular}

$A N A$ antinuclear antibody, $b D M A R D$ biologic disease-modifying antirheumatic drug, $d s$ double-stranded, ESR erythrocyte sedimentation rate, $F B C$ full blood count, $L F T$ liver function tests, $T B$ tuberculosis, $U \& E$ urea and electrolytes

monitoring (inflated to 2015-2016 prices using the Personal Social Services Research Unit inflation index [38] where necessary).

The severity of arthritis and psoriasis can have an impact on healthcare costs in patients with PsA [13]. Therefore, in addition to the resource use and costs associated with treatment, costs related to health states measured with HAQ and PASI were included for each cycle in the model. These costs were based on algorithms that provided estimates of direct costs based on absolute HAQ and PASI scores in the modelled cohort, and included hospitalisations, surgical interventions, ambulatory and community care, and rheumatoid arthritis medication [12, 39]. PsA patients with moderate-to-severe psoriasis whose psoriasis was controlled (PASI75) had lower estimated annual costs than their counterparts whose psoriasis was not controlled ( $£ 72$ vs $£ 2,552$ ). In addition, based on an earlier estimate that conventional DMARDs account for $15 \%$ of the direct costs [39], an adjustment factor of 0.85 was applied to bDMARD costs to avoid potential double counting with other acquisition costs that were applied separately in the model.

For patients in the BSC health state, the only costs applied were those related to HAQ and PASI without applying an adjustment factor. For those receiving bDMARD therapy during the trial or continuous treatment periods, costs associated with serious adverse events requiring hospitalisation were not included in the base-case analysis because of limited data regarding the incidence of such events for some bDMARDs and an expected relatively small contribution to overall costs and outcomes. All costs and benefits were 
Table 4 Unit costs for drug acquisition, physician visits, injection training and monitoring of subcutaneous bDMARDs

\begin{tabular}{lll}
\hline Resource & Cost $^{\mathrm{a}}$ & Source \\
\hline $\begin{array}{l}\text { Drug acquisition costs (list prices) } \\
\text { Ixekizumab 80 mg prefilled pen or syringe }\end{array}$ & $£ 1,125$ per dose & MIMS (2017) [47] \\
Secukinumab 300 mg prefilled pen or syringe & $£ 1,218.78$ per dose & MIMS (2017) [47] \\
Ustekinumab 45 mg prefilled syringe & $£ 2,147.00$ per dose & MIMS (2017) [47] \\
Ustekinumab 90 mg prefilled syringe & $£ 2,147.00$ per dose & MIMS (2017) [47] \\
Physician, injection training and monitoring costs & & \\
Rheumatologist visit & $£ 142.74$ & DoH (2016) [48] \\
Injection training (1 h) & $£ 43.00$ & PSSRU (2016) [38] \\
FBC & $£ 3.00$ & DoH (2016) [48] \\
LFT & $£ 1.00$ & DoH (2016) [48] \\
U\&E & $£ 1.00$ & DoH (2016) [48] \\
ESR & $£ 3.00$ & DoH (2016) [48] \\
Chest X-ray & $£ 30.00$ & DoH (2016) [48] \\
TB Heaf test & $£ 8.91$ & Rodgers et al. (2011) [12] \\
ANA test & $£ 3.00$ & DoH (2016) [48] \\
ds DNA test & $£ 3.00$ & DoH (2016) [48] \\
\hline
\end{tabular}

$A N A$ antinuclear antibody, $b D M A R D$ biologic disease-modifying antirheumatic drug, $D o H$ Department of Health (NHS reference cost), $d s$ double-stranded, ESR erythrocyte sedimentation rate, $F B C$ full blood count, LFT liver function tests, MIMS Monthly Index of Medical Specialties, PSSRU Personal Social Services Research Unit, $T B$ tuberculosis, $U \& E$ urea and electrolytes

${ }^{a}$ Drug acquisition costs for the year 2017. Unit costs for physician visits, injection training and monitoring were based on the latest reference cost schedule in place (2015-2016) or were inflated to 2015-2016 prices using the Personal Social Services Research Unit inflation index where necessary discounted at an annual rate of $3.5 \%$ as per the NICE reference case [40].

\subsection{Sensitivity Analyses}

Sensitivity analyses were undertaken to explore the inherent uncertainty in the base-case analysis, which incorporated various assumptions and data from several different sources. These analyses included one-way (deterministic) sensitivity analyses, a probabilistic sensitivity analysis and scenario analyses. In the one-way sensitivity analysis, where one variable was altered at a time to assess the effect on results, most input parameters were varied by $\pm 20 \%$ of the mean value, as $95 \%$ confidence interval (CI) values were not available. Notable exceptions were ranges of values used for the efficacy of bDMARDs and BSC $( \pm 10 \%$ of mean values from the NMA), the annual discontinuation rate $(95 \% \mathrm{CI})$, the discount rate for costs and health utilities $(1.5 \%, 6 \%)$, and physician and monitoring costs ( \pm 1 visit or test).

In addition, a probabilistic sensitivity analysis was conducted by assigning distributions to input parameters and sampling from these distributions in 1000 simulations. For efficacy inputs, instead of applying parametric distributions, the CODA (Convergence Diagnostics and Output Analysis) output of the Bayesian NMA was used [35, 41]. A beta distribution was used for values that ranged between 0 and 1 , and a gamma distribution was assumed for all other parameters that ranged between zero and infinity. Input parameters for this analysis included PsARC and PASI response rates, baseline HAQ and PASI, withdrawal rates, changes in HAQ and health utility, mortality and various costs. The scenario analysis included alternative inputs for health state costs, HAQ rebound options, the EQ-5D utility algorithm, the definition of response (i.e. combined criteria of PsARC and either PASI75, PASI90 or PASI100) and an analysis of subgroups with less severe or no psoriasis.

\section{Results}

In the base-case analysis in patients with PsA and concomitant moderate-to-severe psoriasis, ixekizumab was associated with lower total costs and higher total qualityadjusted life-years (QALYs) than secukinumab in both bDMARD-naïve and bDMARD-experienced patients. Although ixekizumab was dominant in both subpopulations, cost savings and QALY gains over secukinumab were small to modest (Table 5). In bDMARD-naïve patients treated with ixekizumab followed by ustekinumab then BSC, total costs over the lifetime horizon of the model were $£ 155,455$, as compared with $£ 155,530$ for secukinumab followed by ustekinumab then BSC (year 2017 values). Total QALYs were also generally similar for both sequences, although they favoured ixekizumab (8.127 
Table 5 Results of the basecase analysis

\begin{tabular}{|c|c|c|c|c|c|c|}
\hline \multirow[t]{2}{*}{ Parameter } & \multicolumn{2}{|c|}{ bDMARD-naïve patients } & \multirow[t]{2}{*}{ Difference } & \multicolumn{2}{|c|}{$\begin{array}{l}\text { bDMARD-experienced } \\
\text { patients }\end{array}$} & \multirow[t]{2}{*}{ Difference } \\
\hline & Ixekizumab & Secukinumab & & Ixekizumab & Secukinumab & \\
\hline Total costs & $£ 155,455$ & $£ 155,530$ & $-£ 75$ & $£ 140,051$ & $£ 140,264$ & $-£ 213$ \\
\hline Total QALYs & 8.127 & 7.989 & +0.138 & 3.996 & 3.875 & +0.121 \\
\hline ICER & Dominant & & & Dominant & & \\
\hline
\end{tabular}

DDMARD biologic disease-modifying antirheumatic drug, ICER incremental cost-effectiveness ratio, $Q A L Y$ quality-adjusted life-years vs 7.989). In bDMARD-experienced patients, the corresponding values for ixekizumab followed by BSC compared with secukinumab followed by BSC were $£ 140,051$ versus $£ 140,264$ for total costs and 3.996 versus 3.875 for total QALYs.

One-way sensitivity analysis in bDMARD-naïve patients showed that base-case results were generally robust to changes in most input parameters with the exception of IL-17A antagonist costs and PsARC response (Fig. 3a). Results were also sensitive to a modification of PsARC response by $\pm 10 \%$ for the IL-17A antagonists, although not to the same extent as costs (Fig. 3a). Results of the one-way sensitivity analysis in bDMARDexperienced patients were generally similar to those in bDMARD-naïve patients in that the base-case results were robust to modifications of most input parameters but were sensitive to changes in ixekizumab and secukinumab costs and PsARC response (Fig. 3b).

Probabilistic sensitivity analysis for bDMARD-naïve patients showed that almost one-third (31.3\%) of the observations were in the southeast quadrant of the cost-effectiveness plane, indicating that ixekizumab was less costly and provided more QALYs than secukinumab. Approximately half $(46.8 \%)$ of the observations were in the northeast quadrant, indicating that ixekizumab was more costly than secukinumab but provided more QALYs. Base-case results were under a willingness-to-pay (WTP) threshold of $£ 20,000$ per QALY gained (Fig. 4a). For bDMARD-experienced patients, $20.7 \%$ and $47.1 \%$ of the observations were in the southeast and northeast quadrants, respectively, and basecase results were also under a WTP threshold of $£ 20,000$ per QALY gained (Fig. 4b).

The cost-effectiveness acceptability curve for bDMARDnaïve patients showed that, compared with secukinumab, ixekizumab had a $90 \%$ probability of being cost-effective at a WTP threshold of $£ 20,000$ per QALY gained and a $96 \%$ probability at a threshold of $£ 30,000$ per QALY gained (Fig. 5a). For bDMARD-experienced patients, the respective probabilities were $85 \%$ and $82 \%$ (Fig. 5 b).

In the scenario analyses where different HAQ rebound options were evaluated, ixekizumab continued to dominate secukinumab regardless of the HAQ rebound scenario in
bDMARD-naïve and -experienced patients. For almost all other scenarios evaluated (see Sect. 2.8), ixekizumab was less costly and provided more QALYs than secukinumab or was associated with an incremental cost-effectiveness ratio (ICER) under a WTP threshold of $£ 30,000$ per QALY gained for bDMARD-naïve and -experienced patients (Table $\mathrm{S} 3$ in the ESM). The only exceptions were in bDMARD-naïve PsA patients with no concomitant psoriasis or mild-to-moderate concomitant psoriasis, where secukinumab provided small advantages in QALYs gained but was associated with higher costs, resulting in ICERs $>£ 175,000$ per QALY gained for secukinumab versus ixekizumab.

\section{Discussion}

This CEA compared the IL-17A antagonists ixekizumab and secukinumab in the management of patients with PsA and concomitant moderate-to-severe plaque psoriasis in the UK. Results of the base-case analysis showed that ixekizumab was associated with lower total costs and higher total QALYs than secukinumab in both bDMARD-naïve and bDMARD-experienced patients, although differences were small to modest. Secukinumab was selected as the comparator in the analysis because decision-makers may wish to select between ixekizumab and secukinumab in view of their shared mechanism of action and since both were reviewed and recommended by NICE with similar conditions of use $[14,15]$.

Our model allows for treatment sequencing (of up to four active treatments) as well as pairwise comparisons. As noted previously, a treatment sequencing approach is reflective of clinical practice in the UK. In addition, there may be costs and benefits associated with the end of a treatment sequence that are only apparent if a sequence is modelled. For example, as BSC is associated with poorer clinical outcomes than active treatments, upstream treatments that reduce the duration of treatment with BSC will be associated with a greater QALY improvement. Modelling treatment sequences may therefore be important to reflect the decision problem accurately. 
A

$$
\text { Tornado ICER ( }(£) \quad \text { - Lower bound = Upper bound }
$$

Ixe Q2W/Q4W - Ust vs Sec 300mg - Ust

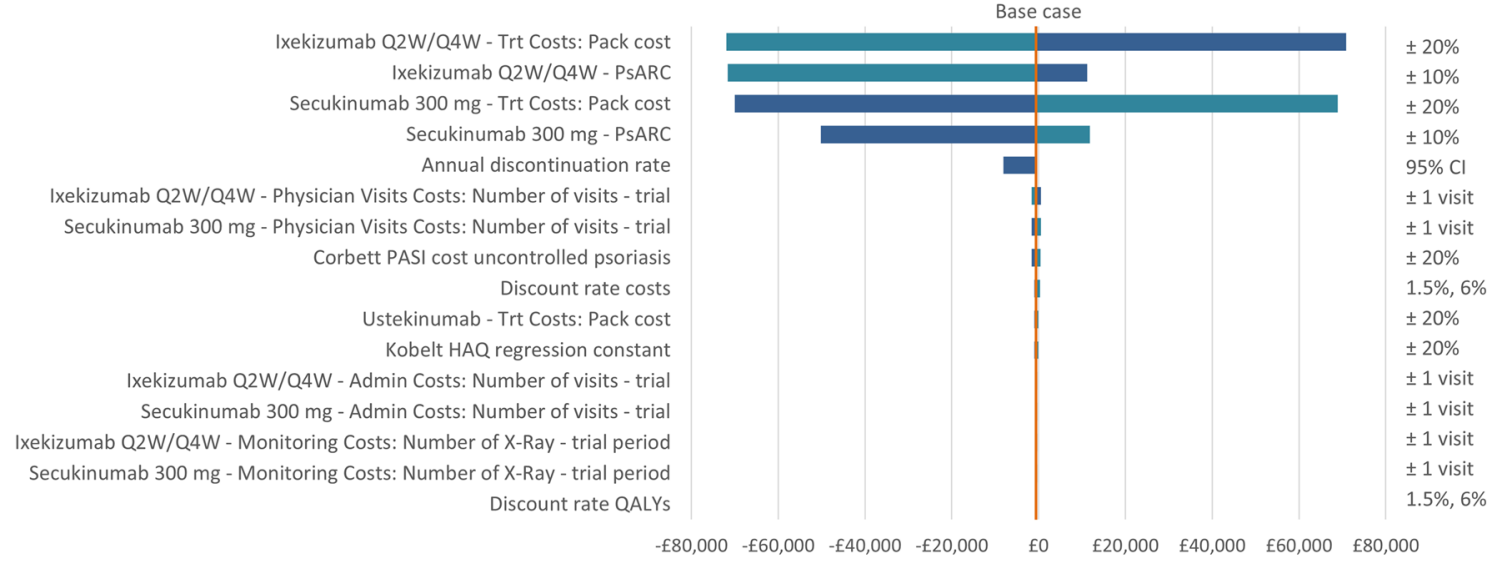

B

Tornado ICER ( $£$ )

- Lower bound

- Upper bound

Ixe Q2W/Q4W vs Sec 300mg

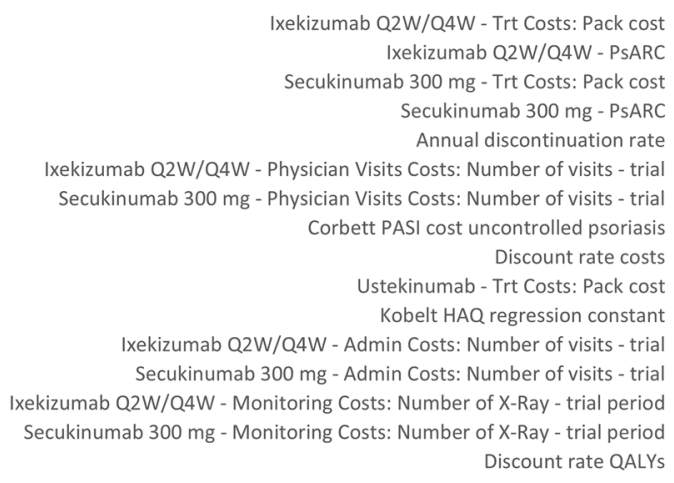

$-€ 160,000$

$-\$ 110,000$
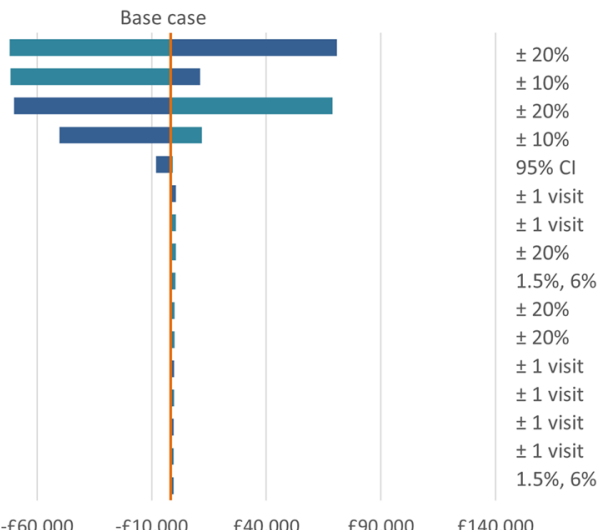

Fig. 3 Results of one-way sensitivity analyses in (a) bDMARDnaïve and (b) bDMARD-experienced patients. Admin administration, $b D M A R D$ biologic disease-modifying antirheumatic drug, $H A Q$ Health Assessment Questionnaire, ICER incremental cost-effective-

The model also allows for the combination of PsARC and PASI as a response criterion, thereby capturing both joint and skin responses in patients with PsA. This may be particularly useful when evaluating clinical benefits of newergeneration bDMARDs, such as IL-17A antagonists in PsA $[42,43]$. The model also has a relatively short cycle length of 1 month, thereby allowing for differential lengths of the trial period for different treatments, and uses ixekizumab trial-based utility equations. In addition, it is a global model that can be adapted for use in other countries where reimbursement and possibly treatment options/sequences may differ from those in the UK.

In the context of PsA and findings from meta-analyses and long-term registry data in the UK $[12,44]$, it is reasonable to

ness ratio, Ixe ixekizumab, PASI Psoriasis Area and Severity Index, PsARC Psoriatic Arthritis Response Criteria, $Q A L Y$ quality-adjusted life-year, $Q x W$ every $x$ weeks, $S e c$ secukinumab, Trt treatment, Ust ustekinumab

assume that transition probabilities for treatment discontinuation beyond the initial induction period (e.g. due to loss of efficacy or treatment intolerability) are constant rather than dependent on identifiable events; therefore, PsA is a disease that is generally well suited to the memoryless nature of a Markov model framework.

Several health economic analyses have been conducted in the treatment of PsA, as highlighted in a recent systematic review [6], and findings of two recent analyses are noteworthy. A Canadian CEA reported that secukinumab either dominated or was cost-effective when compared with all other licensed bDMARDs in treating active PsA in bDMARD-naïve and -experienced populations [45]. However, ixekizumab was not included in the analysis. In 


\section{A \\ Scatter plot \\ Ixe Q2W/Q4W - Ust vs Sec 300mg - Ust}

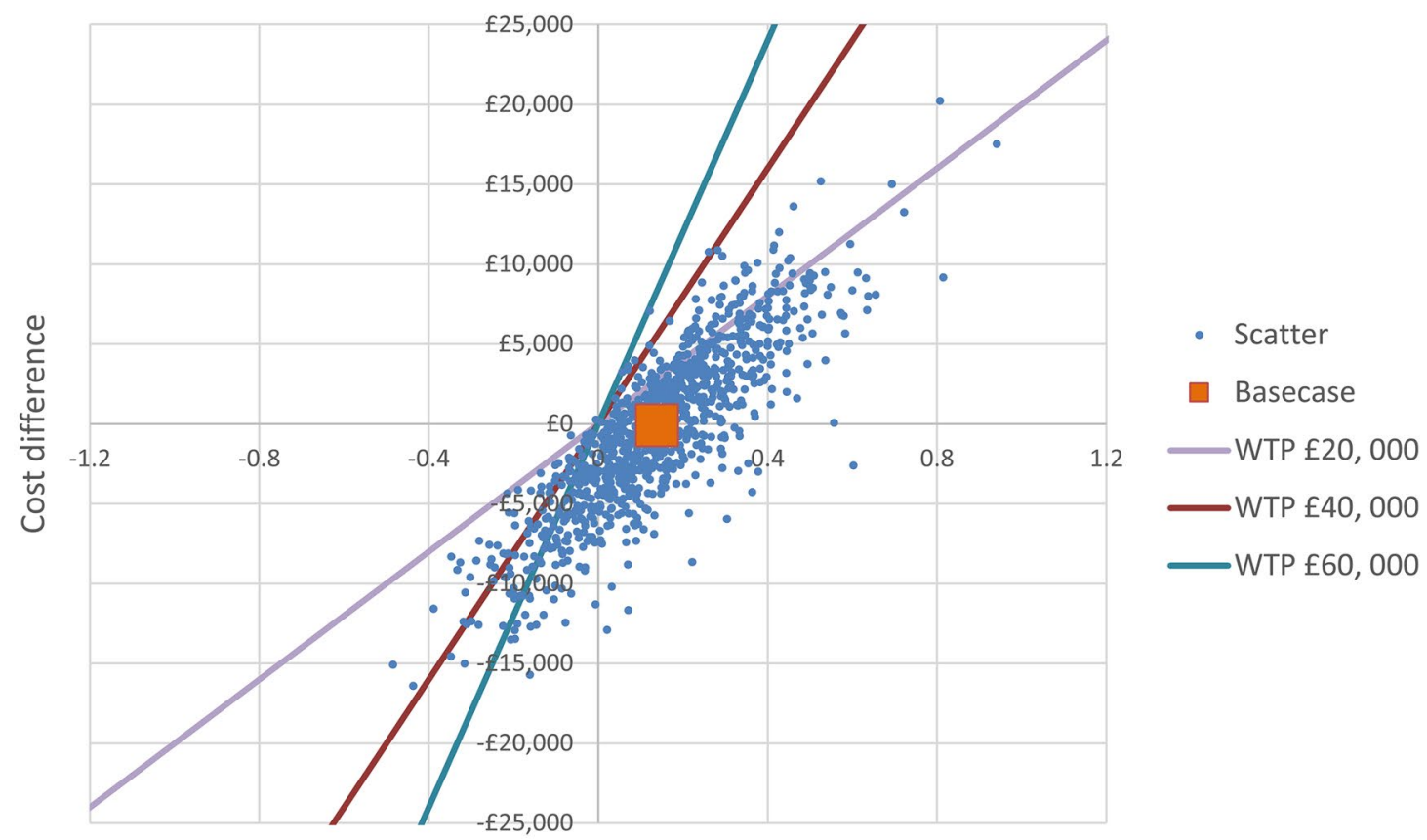

QALY difference

B Ixe Q2W/Q4W vs Sec 300mg

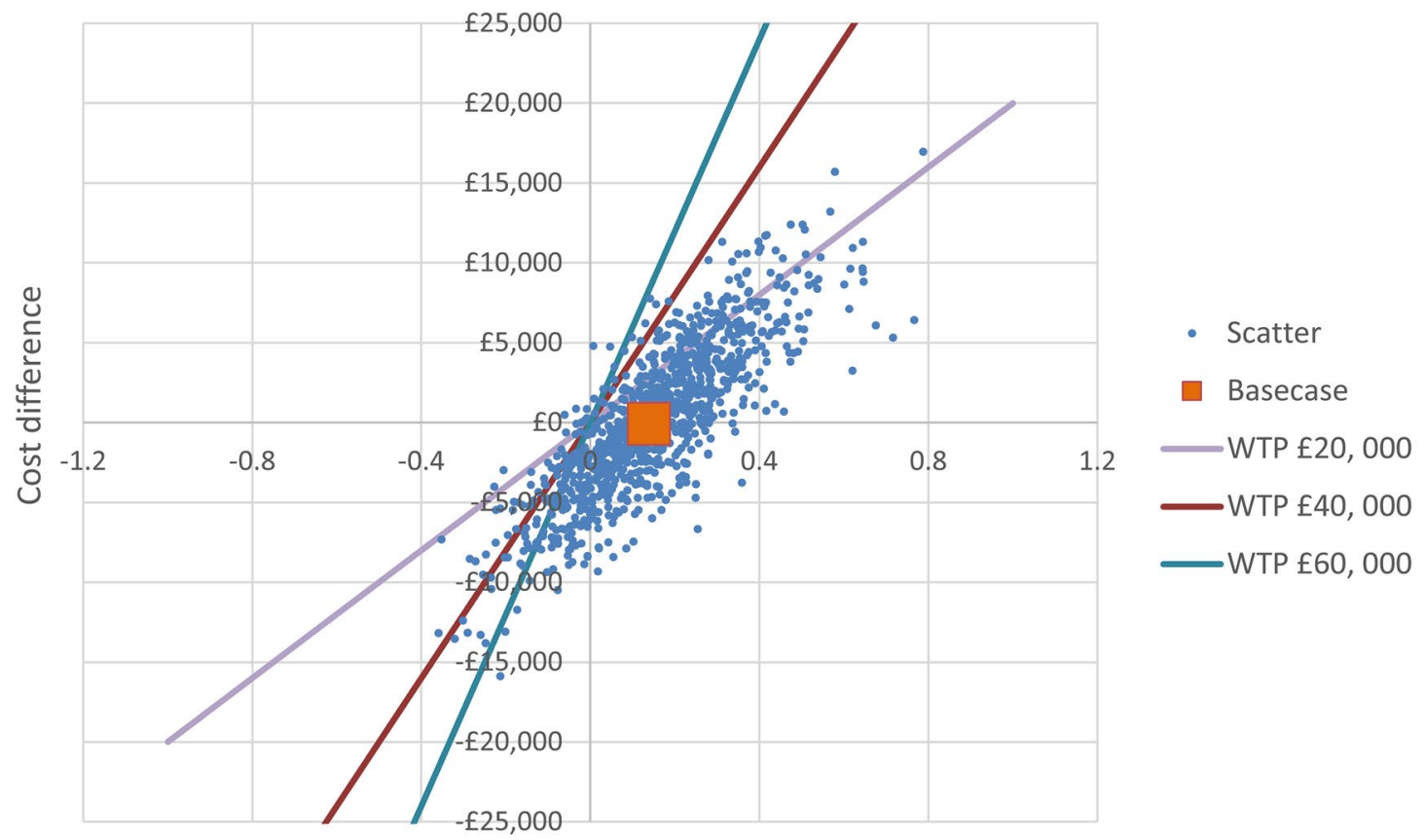

QALY difference 
4Fig. 4 Results of probabilistic sensitivity analyses in (a) bDMARDnaïve and (b) bDMARD-experienced patients. bDMARD biologic disease-modifying antirheumatic drug, Ixe ixekizumab, $Q A L Y$ quality-adjusted life-year, $Q x W$ every $x$ weeks, Sec secukinumab, Ust ustekinumab, WTP willingness to pay

the UK, a systematic review and CEA evaluated the costeffectiveness of secukinumab and certolizumab pegol versus other relevant comparators for treating active PsA following an inadequate response to DMARDs [13]. Results indicated that both of these agents may be an effective use of NHS resources depending on the subpopulation and psoriasis severity, although an important study limitation was data availability.

Data availability was also a limitation of our analysis, as some of the underlying data (e.g. cost estimates for health states) were based on relatively old studies and/or conducted

A Cost-Effectiveness Acceptability Curve

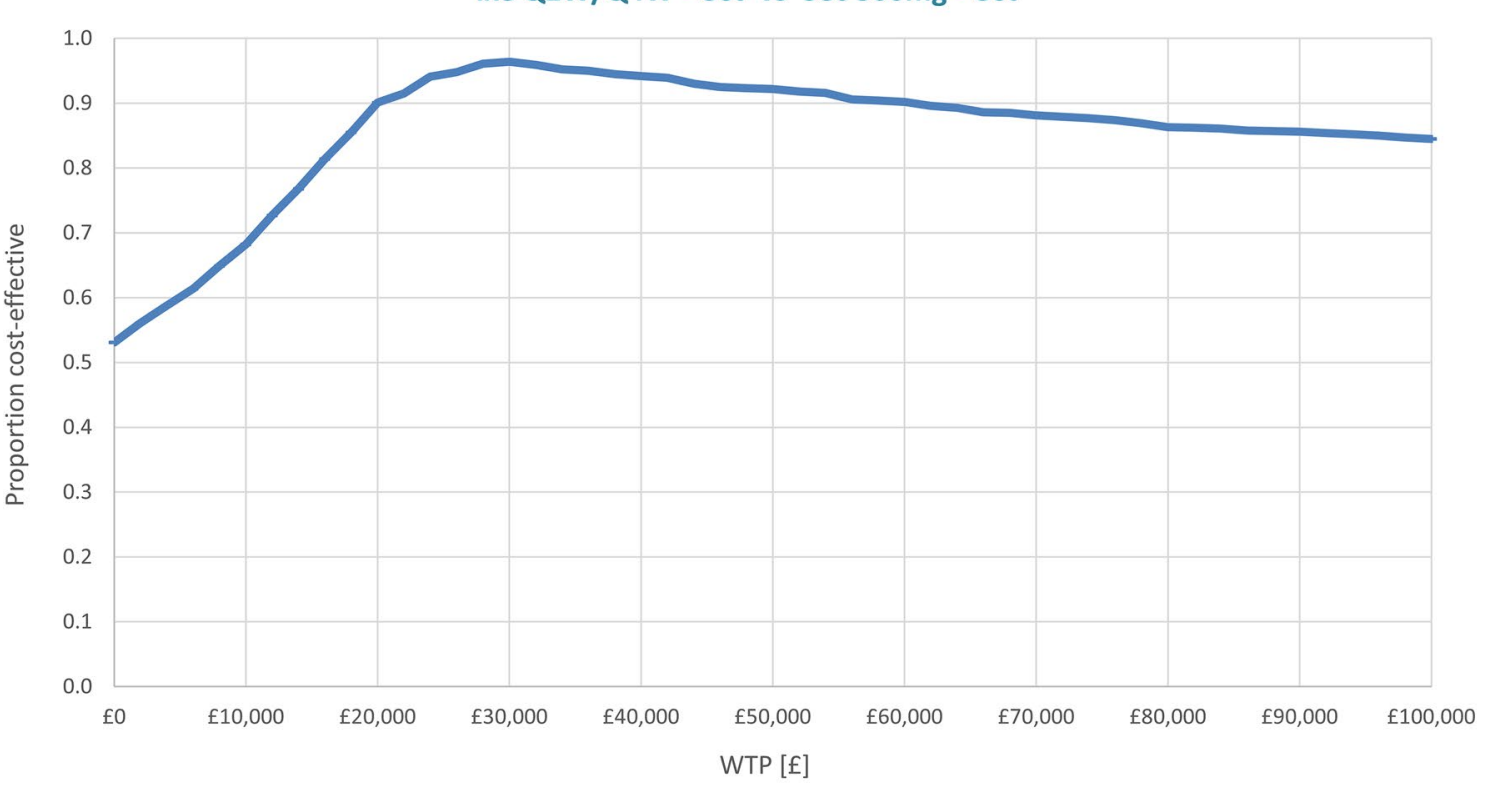

B

Cost-Effectiveness Acceptability Curve

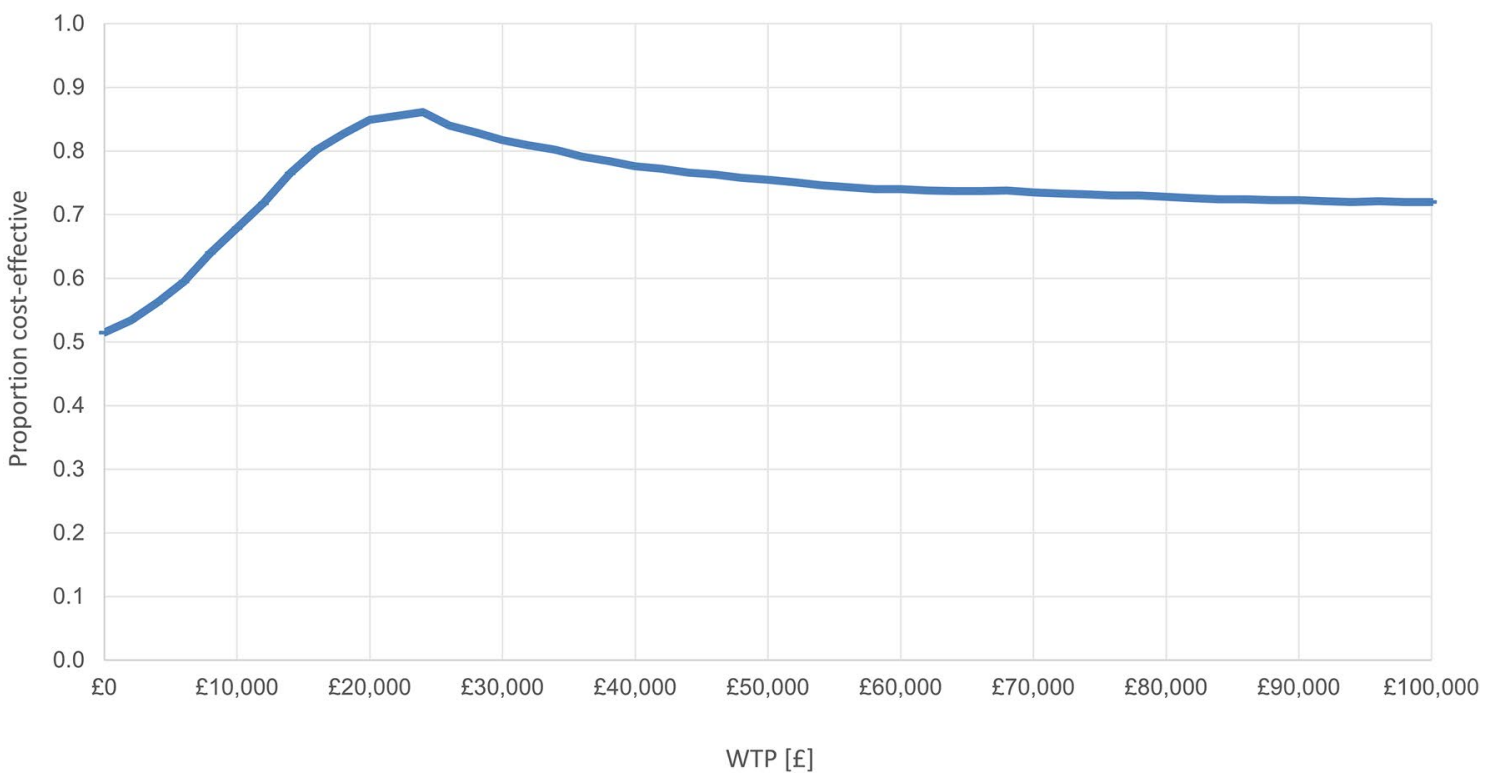

Fig. 5 Cost-effectiveness acceptability curves for (a) bDMARD-naïve and (b) bDMARD-experienced patients. $b D M A R D$ biologic disease-modifying antirheumatic drug, Ixe ixekizumab, $Q x W$ every $x$ weeks, Sec secukinumab, Ust ustekinumab, WTP willingness to pay 
in rheumatoid arthritis patients (e.g. [39]). However, these sources are still used in assessments of bDMARDs for the treatment of PsA [12, 13, 16-19], as the ability to carry out similar research has been hindered by a lack of respective PsA cohorts to date, highlighting a potential area for further research. There is also, generally, a lack of underlying data on treatments constituting BSC and their efficacies. Also, as noted in Sect. 2.5, responses/utilities at the end of the trial period were applied retrospectively throughout the trial period because data are not available for earlier timepoints across treatments.

Another possible limitation of our analysis is that it used list prices for drugs rather than confidential, preferentially priced patient access scheme costs in the UK. In addition, other factors that might drive treatment decisions (e.g. patient preference for the number of injections, injection device design or availability of longer-term safety data) were not included in the model. Also, the model relied on efficacy input data from a NMA, as there were no head-to-head comparative trials between ixekizumab and secukinumab or other bDMARDs in PsA in general, or in patients with PsA and concomitant moderate-to-severe psoriasis, which was the target population in our analysis. Nevertheless, one of the main findings of the NMA was that there were generally few statistically significant differences between most treatments [35].

There is also uncertainty regarding the annual discontinuation rate of $16.5 \%$ that was used in the base-case analysis. Although this was in accordance with previous models and with NICE submissions [12, 13], further research is warranted. In addition, while we did not employ any of the standard checklists for model validity, we have carried out a thorough test of the functionality, and the model has been extensively validated by an external health outcomes expert.

Although total costs and QALYs were quite similar for ixekizumab and secukinumab, with a modest advantage to ixekizumab for both parameters in bDMARD-naïve and -experienced patients with PsA and concomitant moderateto-severe psoriasis, we believe the findings of our analysis still provide insights that may be helpful for healthcare decision-makers when allocating resources.

\section{Conclusion}

Findings of this cost-effectiveness analysis in patients with PsA and concomitant moderate-to-severe psoriasis in the UK showed that, when list prices were used, ixekizumab provided more QALYs at a lower cost than secukinumab in both bDMARD-naïve and -experienced patients, although the total cost and QALY differences were small and the base-case results were most sensitive to changes in costs for these IL-17A antagonists. Results were generally robust to modifications of most other input parameters. In light of the relatively small magnitudes of cost and QALY differences, other factors not included in our model, such as patient preferences for number of injections and confidential price discounts, may be important to consider in clinical decision-making.

Acknowledgements The authors would like to acknowledge Greg Plosker and Karen Goa (Rx Communications, Mold, UK) for their medical writing assistance during the preparation of this manuscript.

Author Contributions BS was involved with the conception and design of the work, the analysis and interpretation of the data and the drafting of the manuscript. CM and ÖA were involved with the conception and design of the work, and the acquisition, analysis and interpretation of the data. GK was involved with the conception and design of the work and the acquisition and interpretation of the data. DN was involved with the conception and design of the work and the interpretation of the data. SK was involved with the conception and design of the work. CS was involved with the acquisition, analysis and interpretation of the data. SH was involved with the conception of the work and the analysis and interpretation of the data. All authors contributed sufficiently to the work and provided critical revision of the manuscript for important intellectual content. All authors give their approval for the manuscript to be submitted to and published in PharmacoEconomics Open and agree to be accountable for all aspects of the work.

Data Availability All data relevant to the study are included in the article or uploaded as supplementary information. Eli Lilly and Company Ltd may be able to consider sharing the executable model upon request, at which point a case-by-case judgement would be made to ensure adherence to company procedures. The executable CEA model is proprietary material and any request will need to be carefully considered.

\section{Compliance with Ethical Standards}

Funding This study was funded by Eli Lilly and Company.

Conflicts of Interest BS, CM and Ö̊ are full-time employees of ICON who were commissioned by Eli Lilly and Company to conduct the analysis for this work. GK, CS and SH are full-time employees of Eli Lilly and Company, receive a salary, and own company stock. DN and SK were full-time employees of Eli Lilly and Company during the inception of the work.

Statement of Human Rights and Animal Welfare This article does not contain any studies with human participants or animals performed by any of the authors.

Open Access This article is licensed under a Creative Commons Attribution-NonCommercial 4.0 International License, which permits any non-commercial use, sharing, adaptation, distribution and reproduction in any medium or format, as long as you give appropriate credit to the original author(s) and the source, provide a link to the Creative Commons licence, and indicate if changes were made. The images or other third party material in this article are included in the article's Creative Commons licence, unless indicated otherwise in a credit line to the material. If material is not included in the article's Creative Commons licence and your intended use is not permitted by statutory regulation or exceeds the permitted use, you will need to obtain permission directly from the copyright holder.To view a copy of this licence, visit $\mathrm{http} / / /$ creativecommons.org/licenses/by-nc/4.0/. 


\section{References}

1. McArdle A, Pennington S, FitzGerald O. Clinical features of psoriatic arthritis: a comprehensive review of unmet clinical needs. Clin Rev Allergy Immunol. 2018;55(3):271-94.

2. Ritchlin CT, Colbert RA, Gladman DD. Psoriatic arthritis. N Engl J Med. 2017;376(10):957-70.

3. National Institute for Health and Care Excellence (NICE). Health technology appraisal. Etanercept, infliximab and adalimumab for the treatment of psoriatic arthritis (review of TA104 and TA125). https://www.nice.org.uk/guidance/ta199/documents/psoriaticarthritis-etanercept-infliximab-golimumab-and-adalimumab-revie w-final-scope2. Accessed 25 April 2019.

4. Kotsis K, Voulgari PV, Tsifetaki N, Machado MO, Carvalho AF, Creed F, Drosos AA, Hyphantis T. Anxiety and depressive symptoms and illness perceptions in psoriatic arthritis and associations with physical health-related quality of life. Arthritis Care Res. 2012;64(10):1593-601.

5. Lee S, Mendelsohn A, Sarnes E. The burden of psoriatic arthritis: a literature review from a global health systems perspective. P T. 2010;35(12):680-9.

6. D'Angiolella LS, Cortesi PA, Lafranconi A, et al. Cost and cost effectiveness of treatments for psoriatic arthritis: a systematic review. Pharmacoeconomics. 2018;36(5):567-89.

7. Kawalec P, Malinowski KP. The indirect costs of psoriatic arthritis: systematic review and meta-analysis. Expert Rev Pharmacoecon Outcomes Res. 2015;15(1):125-32.

8. Greenberg JD, Palmer JB, Li Y, Herrera V, Tsang Y, Liao M. Healthcare resource use and direct costs in patients with ankylosing spondylitis and psoriatic arthritis in a large US cohort. J Rheumatol. 2016;43(1):88-96.

9. European Medicines Agency. Ixekizumab $\left(\right.$ Taltz $\left.^{\circledR}\right)$ : summary of product characteristics. https://www.ema.europa.eu/docs/en_GB/ document_library/EPAR_-_Product_Information/human/003943/ WC500205804.pdf. Accessed 6 April 2018.

10. Datapharm Ltd. Electronic Medicines Compendium: secukinumab $\left(\right.$ Cosentyx $\left.{ }^{\circledR}\right)$ : summary of product characteristics. https://www. medicines.org.uk/emc/product/3669/smpc\#main. Accessed 21 July 2018.

11. Woolacott N, Bravo Vergel Y, Hawkins N, et al. Etanercept and infliximab for the treatment of psoriatic arthritis: a systematic review and economic evaluation. Health Technol Assess. 2006;10(31):iii-iv, xiii-xvi, 1-239.

12. Rodgers M, Epstein D, Bojke L, Yang H, Craig D, Fonseca T, et al. Etanercept, infliximab and adalimumab for the treatment of psoriatic arthritis: a systematic review and economic evaluation. Health Technol Assess. 2011;15(10):i-xxi, 1-329.

13. Corbett M, Chehadah F, Biswas M, Moe-Byrne T, Palmer S, Soares M, et al. Certolizumab pegol and secukinumab for treating active psoriatic arthritis following inadequate response to disease modifying anti-rheumatic drugs: a systematic review and economic evaluation. Health Technol Assess. 2017;21(56):1-326.

14. National Institute for Health and Care Excellence (NICE). Technology appraisal guidance. Ixekizumab for treating active psoriatic arthritis after inadequate response to DMARDs. https://www. nice.org.uk/guidance/ta537. Accessed 13 Sept 2019.

15. National Institute for Health and Care Excellence (NICE). Certolizumab pegol and secukinumab for treating active psoriatic arthritis after inadequate response to DMARDs. Technology appraisal guidance 445. 24 May 2017. https://www.nice.org.uk/guidance/ ta445/resources/certolizumab-pegol-and-secukinumab-for-treat ing-active-psoriatic-arthritis-after-inadequate-response-to-dmard s-pdf-82604786303941. Accessed 11 Sept 2018.

16. Bojke L, Epstein D, Craig D, Rodgers M, Woolacott N, Yang $\mathrm{H}$, Sculpher M. Modelling the cost-effectiveness of biologic treatments for psoriatic arthritis. Rheumatology. 2011;50(Suppl 4):39-47.

17. Cawson MR, Mitchell SA, Knight C, Wildey H, Spurden D, Bird A, Orme ME. Systematic review, network meta-analysis and economic evaluation of biological therapy for the management of active psoriatic arthritis. BMC Musculoskelet Disord. 2014;15(1):26.

18. Cummins E, Asseburg C, Punekar YS, Shore E, Morris J, Briggs A, Fenwick E. Cost-effectiveness of infliximab for the treatment of active and progressive psoriatic arthritis. Value Health. 2011;14(1):15-23.

19. Cummins E, Asseburg C, Prasad M, Buchanan J, Punekar YS. Cost effectiveness of golimumab for the treatment of active psoriatic arthritis. Eur J Health Econ. 2012;13(6):801-9.

20. National Office of Statistics. Past and projected mortality rates (qx) from the 2014-based UK life tables. https://www.ons.gov.uk/ peoplepopulationandcommunity/birthsdeathsandmarriages/death s/adhocs/005127pastandprojectedmortalityratesqxfromthe2014b asedlifetablesfortheuk0to105yrs1981 to2064. Accessed 12 April 2018.

21. Ali Y, Tom BD, Schentag CT, Farewell VT, Gladman DD. Improved survival in psoriatic arthritis with calendar time. Arthritis Rheum. 2007;56(8):2708-14.

22. Pan Mersey Area Prescribing Committee. Psoriatic arthritis and peripheral spondyloarthropathy: high cost drugs pathway (version 6.1). https://www.panmerseyapc.nhs.uk/media/2101/psaspahigh cost_pathway.pdf. Accessed 25 April 2019.

23. Greater Manchester Medicines Management Group. Harmonised biologics pathway for ankylosing spondylitis (including nonradiographic axial spondyloarthritis-AS) and psoriatic arthritis (PsA). 2018. https://gmmmg.nhs.uk/docs/guidance/GMMMG -AS-PsA-pathway-v4-2a.pdf. Accessed 23 July 2018.

24. Siebert U, Alagoz O, Bayoumi AM, et al. State-transition modeling: a report of the ISPOR-SMDM Modeling Good Research Practices Task Force-3. Value Health. 2012;15:812-20.

25. Naimark DMJ, Kabboul NN, Krahn MD. The half-cycle correction revisited: redemption of a kludge. Med Decis Making. 2013;33:961-70.

26. Briggs A, Sculpher M. An introduction to Markov modelling for economic evaluation. Pharmacoeconomics. 1998;13(4):397-409.

27. Mease PJ, Antoni CE, Gladman DD, et al. Psoriatic arthritis assessment tools in clinical trials. Ann Rheum Dis. 2005;64:49-54.

28. Fransen J, Antoni C, Mease PJ, et al. Performance of response criteria for assessing peripheral arthritis in patients with psoriatic arthritis: analysis of data from randomised controlled trials of two tumour necrosis factor inhibitors. Ann Rheum Dis. 2006; 65:1373-8.

29. Kavanaugh A, Cassel S. The assessment of disease activity and outcomes in psoriatic arthritis. Clin Exp Rheumatol. 2005;23(5 Suppl 39):S142-7.

30. Wong PC, Leung YY, Li EK, Tam LS. Measuring disease activity in psoriatic arthritis. Int J Rheumatol. 2012. https://doi. org/10.1155/2012/839425.

31. Mease PJ, van der Heijde D, Ritchlin CT, Okada M, Cuchacovich RS, Shuler CL, Lin CY, Braun DK, Lee CH, Gladman DD. Ixekizumab, an interleukin-17A specific monoclonal antibody, for the treatment of biologic-naive patients with active psoriatic arthritis: results from the 24-week randomised, double-blind, placebo-controlled and active (adalimumab)-controlled period of the phase III trial SPIRIT-P1. Ann Rheum Dis. 2017;76(1):79-87.

32. Nash P, Kirkham B, Okada M, Rahman P, Combe B, Burmester GR, Adams DH, Kerr L, Lee C, Shuler CL, Genovese M. Ixekizumab for the treatment of patients with active psoriatic arthritis and an inadequate response to tumour necrosis factor inhibitors: results from the 24-week randomised, double-blind, 
placebo-controlled period of the SPIRIT-P2 phase 3 trial. Lancet. 2017;389(10086):2317-27.

33. Braun J. New targets in psoriatic arthritis. Rheumatology. 2016;55:30-7.

34. Gossec L, Smolen JS, Ramiro S, et al. European League Against Rheumatism (EULAR) recommendations for the management of psoriatic arthritis with pharmacological therapies: 2015 update. Ann Rheum Dis. 2016;75:499-510.

35. Ruyssen-Witrand A, Perry R, Watkins C, et al. Efficacy and safety of biologics in psoriatic arthritis: a systematic literature review and network meta-analysis. RMD Open. 2020;6:e001117.

36. Corbett M, Sideris E, Palmer S, Harden M, Woolacott N, Bojke L. Apremilast for treating active psoriatic arthritis: a single technology appraisal. York: CRD and CHE Technology Assessment Group; 2015.

37. Kyle S, Chandler D, Griffiths CE, Helliwell P, Lewis J, McInnes I, Oliver S, Symmons D, McHugh N. Guideline for anti-TNF- $\alpha$ therapy in psoriatic arthritis. Rheumatology. 2005;44(3):390-7.

38. Curtis L, Burns A. Unit costs of health and social care 2016. Canterbury: Personal Social Services Research Unit, University of Kent; 2016. https://www.pssru.ac.uk/project-pages/unit-costs/ unit-costs-2016/. Accessed 9 Nov 2018.

39. Kobelt G, Jonsson L, Lindgren P, et al. Modeling the progression of rheumatoid arthritis: a two-country model to estimate costs and consequences of rheumatoid arthritis. Arthritis Rheum. 2002;46(9):2310-9.

40. National Institute for Health and Care Excellence (NICE). Guide to the methods of technology appraisal. 2013. https://www.nice. org.uk/process/pmg9/chapter/foreword. Accessed 9 Nov 2018.
41. Dias S, Sutton AJ, Welton NJ, et al. Evidence synthesis for decision making 6: embedding evidence synthesis in probabilistic cost-effectiveness analysis. Med Decis Making. 2013;33:671-8.

42. Betteridge N, Boehncke W-H, Bundy C, et al. Promoting patient-centred care in psoriatic arthritis: a multidisciplinary European perspective on improving the patient experience. JEADV. 2015;30:576-85.

43. Gottleib AB, Strand V, Kishimoto M. Ixekizumab improves patient-reported outcomes up to 52 weeks in bDMARD-naïve patients with active psoriatic arthritis (SPIRIT-P1). Rheumatology. 2018;57(10):1777-888.

44. Fagerli KM, Kearsley-Fleet L, Watson KD, et al. Long-term persistence of TNF-inhibitor treatment in patients with psoriatic arthritis. Data from the British Society for Rheumatology Biologics Register. RMD Open. 2018;4:e00596.

45. Goeree R, Chiva-Razavi S, Gunda P, et al. Cost-effectiveness analysis of secukinumab for the treatment of active psoriatic arthritis: a Canadian perspective. J Med Econ. 2018;21(2):163-73.

46. National Institute for Health and Care Excellence (NICE). Ustekinumab for treating active psoriatic arthritis. Technology appraisal guidance 340. 2015. https://nice.org.uk/guidance/ta340. Accessed 23 July 2018.

47. Monthly Index of Medical Specialties. Online database of drug prices. 2017. https://www.mims.co.uk/. Accessed 9 Nov 2018.

48. Department of Health. NHS reference costs 2015 to 2016. London: DoH; 2016. https://www.gov.uk/government/publications/ nhs-reference-costs-2015-to-2016. Accessed 9 Nov 2018.

49. Poole C, Lebmeier M, Ara R, et al. Estimation of health care costs as a function of disease severity in people with psoriatic arthritis in the UK. Rheumatology (Oxford). 2010;49:1949-56. 